\title{
Augmentation Plating in Treating Non-Union Femur Fracture After Intra-Medullary Nailing
}

\author{
Ahmed A Khalifa* FRCS (Tr \& Ortho), MSc \\ Assistant lecturer orthopedic and traumatology, Qena faculty of medicine and its university hospital, South Valley university, Qena, Egypt \\ *Corresponding author: Ahmed A Khalifa, FRCS (Tr \& Ortho), MSc, Assistant lecturer orthopedic and traumatology, Qena faculty of medicine and its \\ university hospital, South Valley university, Qena, Egypt, Email: ahmed_adel0391@med.svu.edu.eg
}

Submission: 㘹 January 30, 2019; Published: 監February 06, 2019

\begin{abstract}
Although intra-medullary nailing in treating femur fractures had been recognized as the gold standard line of management, it carries the risk of non-union reaching up to $3 \%$, many techniques had been described for management femur fracture non-union after nailing such as exchange nailing, exchange plating and plate augmentation leaving the nail in situ, the aim of this review is to discuss the option of augmentation plating.
\end{abstract}

\section{Introduction}

Intra-medullary nails (IMN) is considered as the gold standard technique for treating long-bone fractures especially femoral diaphysis fractures4, since its initial introduction in the 1970s [1,2]. The use of IMN in communicated fractures is beneficial, with greater mechanical stability and reduction of internal bending, also less surgical damage which reduces risk of infection compared to plate fixation [3]. However, IMN has some disadvantages including reaming trauma, technical difficulties, broken nails and the fracture bone non-union [4].

The non-union rate of fracture union following IMN ranges from 0.5 to $3 \%$; the most common type of the non-union is the hypertrophic type [5,6]. Many factors can contribute to failure of bone union after IMN, Johnson et al. [7] proposed that the remaining rotational instability after nailing which may reach up to $10^{\circ}-15^{\circ}$ rotational movement, considered to be the main factor resulting in fracture non-union. Many secondary treatment strategies were developed for fracture non-union after IMN fixation, including: reamed and exchange nailing, exchange plating, nail dynamization and augmentation plating $[8,9]$.

\section{Why to augmentation plating is preferred?}

Weresh et al. [10] suggested the re-evaluation of routine exchange nailing which was considered as the gold standard technique to treat non-union after femur fracture nailing, as union obtained in only $53 \%$ of the patients received exchange nailing in their series, with a significant number of patients required additional procedures to achieve fracture healing. Heng et al. [9] in 1997 recognised that residual instability in diaphyseal femur fracture treated with IMN is the leading cause for non-union, so they got the idea to apply an "augmentative" plate (Figure 1) keeping the nail in situ in a series of 17 non-united femoral fractures that were primarily treated with IMN, they reported $100 \%$ fracture union at a mean time of 7 months without complications, and concluded that plate augmentation provided mechanical stability which resulted in fracture union.

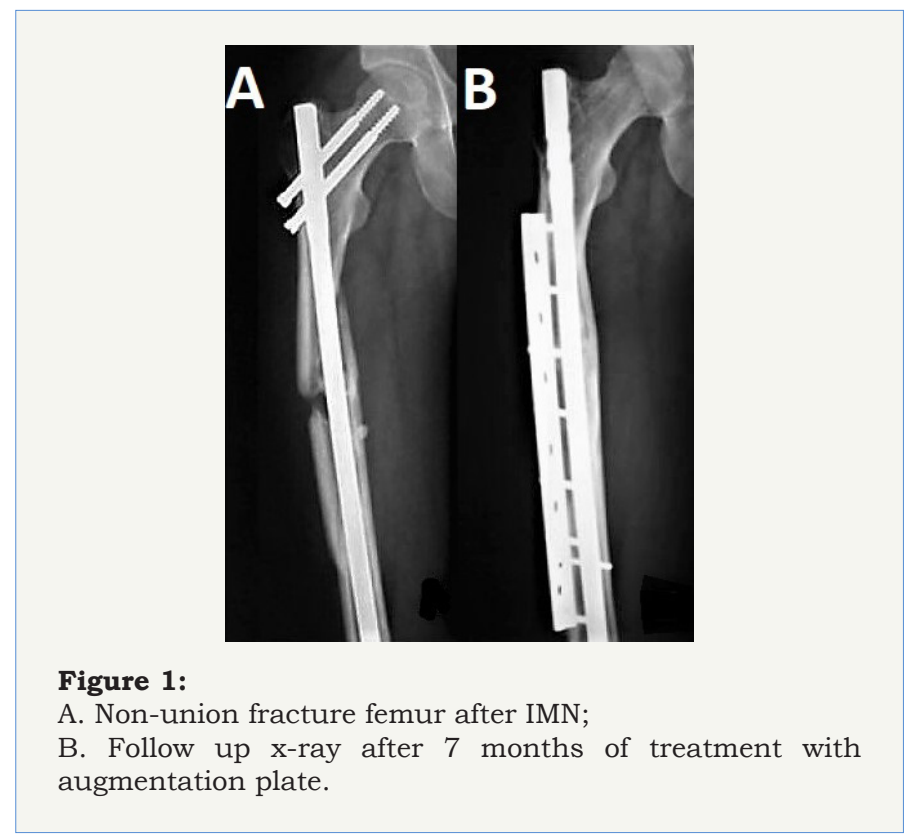

Since this initial description by Heng et al. [9] many surgeons adopted this technique and there have been several reports confirming the high efficacy of plate augmentation in the management of femur diaphyseal aseptic non-unions [11]. Comparing exchange reamed nailing with augmentation plating in treating femoral fracture non-union after nailing, Park et al. [12] in their series failed to achieve union in 5 patients ( $72 \%$ failure) with exchange nailing, however 11 patients (100\% success) treated with augmentation 
plating achieved bony union, they suggested that augmentation plating with the add of autogenous bone grafting is a better option than exchange nailing alone in dealing with femur fracture nonunion after nailing.

Somford et al. [13] in their review has summarised current operative treatments (augmentation plating, exchange nailing and exchange plating) for femoral shaft non-union and concluded that augmentation plating is the best treatment of choice. To verify the usefulness of the technique for the management of long bone diaphyseal aseptic non-unions, a review of the studies carried out to compare different techniques was conducted by Garnavos [11], where three studies compared augmentation plating with exchange nailing and one compared augmentation plating with plating after removal of the nail (exchange plating), best results regarding healing of the non-union as well as operative time and return to activities were found with augmentation plating in all studies reviewed.

Further reports regarding augmentation plating in femoral non-union leaving the nail in situ obtained satisfactory clinical results, with a union rate of approximately $100 \%$ and a union time of approximately 6 months [14-16]. The success of this technique over other advocated techniques can be attributed to a better mechanical rigidity as had been shown in a cadaveric femur fracture model by Park et al. [17] where they made a comparison between plate augmentation leaving the nail in situ and interlocking the nail, the results showed statistically significant differences in both bending load and torsional torque at an angle of $15^{\circ}$ between the two techniques.

The most commonly used plate for augmentation is the broad DCP, with the advantage of having an alternating screw holes which enables the insertion of the screws in front or behind the nail (inserted obliquely to side step the nail) as a bi-cortical screw whenever possible, if not, a uni-cortical screw can be used folding the lateral aspect of the femoral shaft [18].

The advantages of plate augmentation $[11,19]$ : usually it requires less skin incision and does not require removal of the nail and further reduction of femur; allows direct exposure of the nonunion site with the ability to remove any fibrous tissue hindering union; eliminating abnormal rotation movement at the fracture site; ability of bone grafting; rare complications; and a simpler shorter operation time with less bleeding compared with other techniques. The nail and most of the callus was kept un-touched with adding a plate leading to a stable construct enough to allow the patients to perform exercise for early functional recovery as well as early full weight bearing.

However, Ateschrang et al. [20] stress that this technique has drawbacks such as the additional incision and the patients' complains that often necessitate the removal of the plate.

\section{Conclusion}

Treating femur fracture with IMN with lack of rotational stability but sufficient blood supply and new bone formation usually cause hypertrophic non-union. Augmentation plating which provides rotational control coupled with leaving the nail in situ which contributes by its load-sharing capacity with good axial and bending strength could perfectly result in fracture healing with better functional outcomes and faster patients' recovery.

\section{References}

1. Klemm K, Schellmann W (1972) Dynamic and static locking of the intramedullary nail. Monatsschrift fur Unfallheilkunde, VersicherungsVersorgungs-und Verkehrsmedizin 75(12): 568-575.

2. Kempf I, Jaeger J, Clavert J, Mochel D, Glaesener R (1978) Intramedullary nailing with reaming. A critical analysis of Kuntscher's principle (author's transl). Revue de chirurgie orthopedique et reparatrice de l'appareil moteur 64(8): 629-634.

3. Rodrigue MEC, Forriol F (2004) Nonunion: general principles and experimental data. Clinical Orthopedics and Related Research (19762007) 419: 4-12.

4. Huang ZL, Yang HL, Xu JK, Xia X, Wang XJ, et al. (2013) Rotary self-locking intramedullary nail for long tubular bone fractures. Chinese medical journal 126(20): 3874-3878.

5. Brinker MR, O'Connor DP (2007) Exchange nailing of ununited fractures. JBJS 89(1): 177-188.

6. Wu CC (2007) Exchange nailing for aseptic nonunion of femoral shaft: a retrospective cohort study for effect of reaming size. Journal of Trauma and Acute Care Surgery 63(4): 859-865.

7. Johnson KD, Tencer AF, Blumenthal S, August A, Johnston D (1986) Biomechanical performance of locked intramedullary nail systems in comminuted femoral shaft fractures. Clinical Orthopaedics and Related Research (206): 151-161.

8. Bellabarba C, Ricci WM, Bolhofner BR (2001) Results of indirect reduction and plating of femoral shaft nonunions after intramedullary nailing. Journal of Orthopaedic Trauma 15(4): 254-263.

9. Ueng SW, Chao EK, Lee SS, Shih CH (1997) Augmentative plate fixation for the management of femoral nonunion after intramedullary nailing. Journal of Trauma and Acute Care Surgery 43(4): 640-644.

10. Weresh MJ, Hakanson R, Stover MD, Sims SH, Kellam JF, et al. (2000) Failure of exchange reamed intramedullary nails for ununited femoral shaft fractures. Journal of Orthopaedic Trauma 14(5): 335-358.

11. Garnavos C (2017) Treatment of aseptic non-union after intramedullary nailing without removal of the nail. Injury 48: S76-S81.

12. Park J, Kim SG, Yoon HK, Yang KH (2010) The treatment of nonisthmal femoral shaft nonunions with im nail exchange versus augmentation plating. Journal of Orthopaedic Trauma 24(2): 89-94.

13. Somford MP, van den Bekerom MP, Kloen P (2013) Operative treatment for femoral shaft nonunions, a systematic review of the literature. Strategies in Trauma and Limb Reconstruction 8(2): 77-88.

14. Chen CM, Su YP, Hung SH, Lin CL, Chiu FY (2010) Dynamic compression plate and cancellous bone graft for aseptic nonunion after intramedullary nailing of femoral fracture. Orthopedics 33(6): 393.

15. Gao Kd, Huang JH, Tao J, Li F, Gao W, et al. (2011) Management of femoral diaphyseal nonunion after nailing with augmentative locked plating and bone graft. Orthopaedic Surgery 3(2): 83-87.

16. Birjandinejad A, Ebrahimzadeh MH, Ahmadzadeh CH (2009) Augmentation plate fixation for the treatment of femoral and tibial nonunion after intramedullary nailing. Orthopedics 32(6): 409.

17. Park K, Kim K, Choi YS (2011) Comparison of mechanical rigidity between plate augmentation leaving the nail in situ and interlocking nail using cadaveric fracture model of the femur. International Orthopaedics 35(4): 581-558.

18. Said GZ, Said HG, El Sharkawi MM (2011) Failed intramedullary nailing of femur: open reduction and plate augmentation with the nail in situ. International Orthopaedics 35(7): 1089-1092. 
19. Choi Y, Kim K (2005) Plate augmentation leaving the nail in situ and bone grafting for non-union of femoral shaft fractures. International Orthopaedics 29(5): 287-290.

20. Ateschrang A, Karavalakis G, Gonser C, Liener U, Freude T, et al. (2013) Exchange reamed nailing compared to augmentation compression plating leaving the inserted nail in situ in the treatment of aseptic tibial non-union: a two-centre study. Wiener klinische Wochenschrift 125(910): 244-253. (c) (i) Creative Commons Attribution 4.0

For possible submissions Click Here

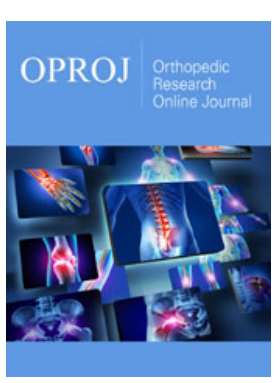

Orthopedic Research Online Journal

\section{Benefits of Publishing with us}

- High-level peer review and editorial services

- Freely accessible online immediately upon publication

- Authors retain the copyright to their work

- Licensing it under a Creative Commons license

- Visibility through different online platforms 